\title{
ATP-induced P2X Receptor-Dependent Large Pore Formation: How Much Do We Know?
}

\author{
Linyu Wei ${ }^{1,2}$, Emily Caseley ${ }^{2}$, Dongliang $\mathrm{Li}^{1 *}$ and Lin-Hua Jiang ${ }^{1,2 *}$ \\ ${ }^{1}$ Department of Physiology and Neurobiology, Xinxiang Medical University, Xinxiang, China, ${ }^{2}$ Faculty of Biological Sciences, \\ School of Biomedical Sciences, University of Leeds, Leeds, UK
}

Keywords: ATP, P2X receptor, large pore formation, ion-permeating pathway

$\mathrm{P} 2 \mathrm{X}$ receptors are a group of homo/hetero-trimeric membrane protein complexes with an integral ion channel that opens upon extracellular adenosine triphosphate (ATP) binding (North, 2002; Khakh and North, 2006). There are seven P2X subunits (P2X1-P2X7), all having a membrane topology of cytosolic N- and C-termini, and two transmembrane segments (TM1 and TM2) connected by a large extracellular domain (Figure 1A; Jiang L.-H. et al., 2013). During application of ATP for a few seconds, P2X receptors function as classical ligand-gated ion channels selectively permeable to small physiological cations such as $\mathrm{Ca}^{2+}, \mathrm{Na}^{+}$, and $\mathrm{K}^{+}$, with the exception of the human P2X5 receptor which exhibits significant $\mathrm{Cl}^{-}$permeability (Bo et al., 2003). Site-directed mutagenesis and functional studies of mammalian P2X receptors, in addition to the determination

OPEN ACCESS

Edited by:

Domenico Tricarico,

University of Bari, Italy

Reviewed by:

Yong Yu,

St. John's University, USA

*Correspondence:

Lin-Hua Jiang

l.h.jiang@leeds.ac.uk:

Dongliang $\mathrm{Li}$

xyld18@126.com

Specialty section:

This article was submitted to Pharmacology of lon Channels and Channelopathies,

a section of the journal

Frontiers in Pharmacology

Received: 30 November 2015 Accepted: 11 January 2016 Published: 29 January 2016

Citation:

Wei L, Caseley E, Li D and Jiang L-H (2016) ATP-induced P2X

Receptor-Dependent Large Pore Formation: How Much Do We Know? Front. Pharmacol. 7:5.

doi: 10.3389/fphar.2016.00005 of the crystal structures of zebrafish P2X4 receptors in the apo, closed state and ATP-bound, open state, have defined the structural basis for ATP binding, ion permeation and channel gating (Kawate et al., 2009; Browne et al., 2010; Hattori and Gouaux, 2012; Jiang L.-H. et al., 2013; Jiang R. et al., 2013). Three ATP-binding pockets are located at the subunit interfaces (Figure 1B), each consisting of highly conserved residues from two adjacent subunits. Occupation of these sites by ATP or its synthetic analog agonists induces conformational changes of the extracellular domain which open the ion-permeating pathway formed by three TM2s (Figures 1C,D). The narrowest part of the ionpermeating pathway or the physical gate is provided by A347 and L351 in the crystal structures of zebrafish P2X4 receptor (Hattori and Gouaux, 2012) or the corresponding residues S342 and L346 in the structural models of rat and human P2X7 receptors (Figure 1D) (Bradley et al., 2011; Browne et al., 2013; Jiang L.-H. et al., 2013).

It is well known that extended application of ATP to activate the P2X receptors for tens of seconds or minutes induces a remarkable increase in membrane permeability to large molecules of up to 900 Daltons, a phenotype often referred to as formation of large pores. This was originally documented in immune cells about three decades ago; ATP permeablized cell membranes to nucleotides (Cockcroft and Gomperts, 1979) and the cationic fluorescent dye ethidium in mast cells (Gomperts, 1983), or the anionic organic dyes lucifer yellow and carboxyfluoresceine in mast cells and macrophages (Bennett et al., 1981; Steinberg and Silverstein, 1987). These immune cells express the formerly named P2Z receptor, which is now known as P2X7 receptor, and heterologous expression of P2X7 receptors conferred ATP-induced large pore formation (Surprenant et al., 1996). Such large pore formation has also been observed during sustained activation of other P2X receptors including $\mathrm{P} 2 \mathrm{X} 2, \mathrm{P} 2 \mathrm{X} 2 / 3, \mathrm{P} 2 \mathrm{X} 2 / 5$, and P2X4 receptors (Khakh et al., 1999; Virginio et al., 1999a,b; Compan et al., 2012). Substantial efforts have been devoted to understanding P2X receptor-dependent large pore formation, but it has been difficult to interpret in a unified mechanism all results from studies examining different receptors in different cell types with different receptor expression levels. Two distinctive mechanisms or hypotheses have been proposed (North, 2002; Pelegrín, 2011; Jiang L.-H. et al., 2013). The first is that persistent activation of $\mathrm{P} 2 \mathrm{X}$ receptors induces dilation of the small ion-permeating pathway. The second, 


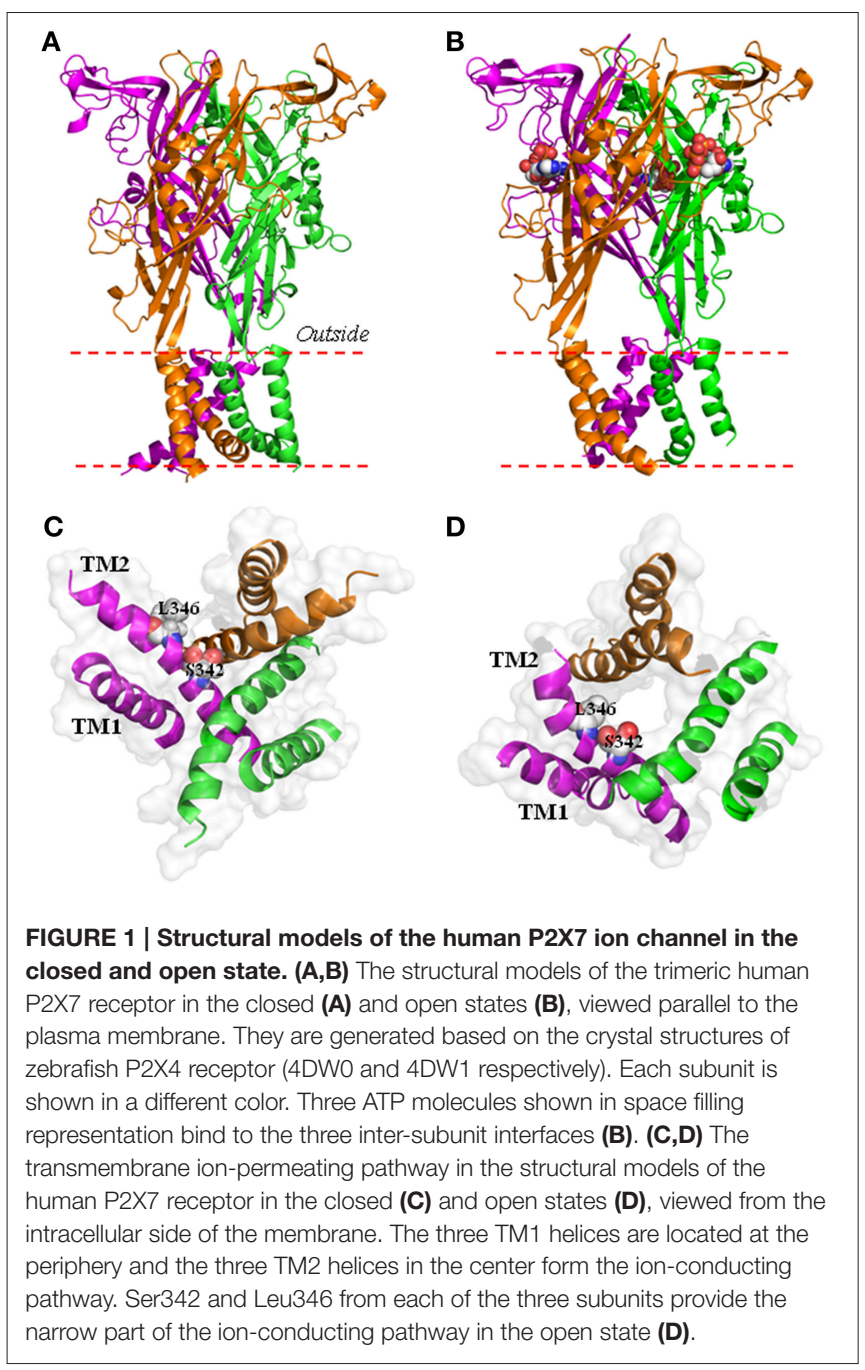

alternative mechanism is that a separate membrane protein interacts with the P2X receptor and forms the large pores upon activation of $\mathrm{P} 2 \mathrm{X}$ receptors. For example, pannexin-1 was shown to form large pores associated with activation of the P2X7 receptor (Pelegrin and Surprenant, 2006).

Two experimental approaches are commonly used to study $\mathrm{P} 2 \mathrm{X}$ receptor-dependent large pore formation. The biophysical approach is to patch-clamp record agonist-induced currents with $\mathrm{Na}^{+}$and $\mathrm{N}$-methyl-D-glucamine $\left(\mathrm{NMDG}^{+}\right.$) being the cation in intracellular and extracellular solutions, respectively (Surprenant et al., 1996; Khakh et al., 1999; Virginio et al., 1999a,b). Under such bi-ionic conditions, if the cell membrane is held at a negative potential, activation of $\mathrm{P} 2 \mathrm{X}$ receptors induces initially outward currents which decline in amplitude as the receptor activation continues. Within tens of seconds these outwards currents change into inward currents. The current reversal potential exhibits a progressive shift toward the less negative direction (example recordings see Surprenant et al., 1996; Khakh et al., 1999; Virginio et al., 1999a,b; Bo et al., 2003; Jiang et al., 2005). If one assumes the intracellular and extracellular cation concentrations remain unchanged during patch-clamp recording, the shift in the current reversal potential can be interpreted as a result of an increase in the $\mathrm{NMDG}^{+}$ permeability of the cell membrane, namely, the open ion channel is poorly permeable to $\mathrm{NMDG}^{+}$at the beginning of receptor activation but significantly increase its $\mathrm{NMDG}^{+}$ permeability as the receptor activation continues. Such an interpretation has led to the pore dilation hypothesis (Virginio et al., 1999a; North, 2002). In addition to the P2X receptors, this biophysical approach has been used to show increases in the permeability during activation of other ion channels such as TRPV1 (Chung et al., 2008; Samways et al., 2008; Munns et al., 2015) and TRPA1 (Chen et al., 2009). The second method to study large pore formation is to use fluorescence microscopy or a fluorescence detection system to monitor agonist-induced intracellular accumulation of fluorescence dyes such as YO-PRO-1 and ethidium, or alternatively agonistinduced progressive loss of preloaded fluorescence dyes such as calcein (example recordings see Surprenant et al., 1996; Virginio et al., 1999a,b; Jiang et al., 2005; Sorge et al., 2012). Measurements of dye uptake (or loss) are often made in more physiological solutions containing micromolar concentrations of fluorescent dye and, by and large, avoid the complications associated with complete removal of extracellular physiological cations. One well-documented example of such complications is that the P2X7 and $\mathrm{P} 2 \mathrm{X} 2 / 5$ ion channels activated in extracellular $\mathrm{NMDG}^{+}$containing solutions were somehow trapped in an open state and did not return to the closed state even minutes after agonist application was discontinued (Jiang et al., 2005; Yan et al., 2008; Compan et al., 2012). Therefore, the findings from measurements of fluorescence dye uptake are of much more biological relevance. The amplitude and rate of fluorescence dye uptake are grossly indicative of large pore formation (e.g., Roger et al., 2010; Browne et al., 2013).

It was assumed in previous studies, despite not always being stated explicitly, that $\mathrm{P} 2 \mathrm{X}$ receptor-dependent large pores serve as the common pathway permeating $\mathrm{NMDG}^{+}$and fluorescent dye uptake. However, this was challenged in a previous study examining the rat $\mathrm{P} 2 \mathrm{X} 7$ receptor heterologously expressed in human embryonic kidney (HEK) 293 cells (Jiang et al., 2005). The study showed that sustained activation of $\mathrm{P} 2 \mathrm{X} 7$ receptor in extracellular $\mathrm{Na}^{+}$-containing solutions induced robust YO-PRO1 dye uptake but, surprisingly, no increase in the $\mathrm{P}_{\mathrm{NMDG}} / \mathrm{P}_{\mathrm{Na}}$. In addition, the study found that removal of a cysteine-rich microdomain in the proximal part of the intracellular Cterminus almost completely abolished agonist-induced reversal potential shift under bi-ionic conditions without compromising agonist-induced YO-PRO-1 uptake. In fact, as compared to the wild-type receptor, expression of the deletion mutant receptor resulted in higher YO-PRO-1 uptake in both $\mathrm{Na}^{+}$-containing and $\mathrm{NMDG}^{+}$-containing solutions (Jiang et al., 2005). These two independent lines of evidence strongly argue against the idea that a same molecular mechanism is used to mediate the entry of both $\mathrm{NMDG}^{+}$and YO-PRO-1 into the cell. In HEK293 cells heterologously expressing the rat $\mathrm{P} 2 \mathrm{X} 2$ receptor, a recent study has found that ATP activation of the P2X2 receptor in extracellular $\mathrm{Na}^{+}$-containing solutions induced no increase in the $\mathrm{P}_{\mathrm{NMDG}} / \mathrm{P}_{\mathrm{Na}}$ (Li et al., 2015). The study has 
elegantly introduced a reservoir model to support the notion that the reversal potential shift simply arises from substantial reduction in the intracellular $\mathrm{Na}^{+}$concentration and increase in the intracellular $\mathrm{NMDG}^{+}$concentration during prolonged $\mathrm{P} 2 \mathrm{X} 2$ ion channel opening. In their model, the P2X2 ion channel is $\mathrm{NMDG}^{+}$-permeable, albeit with the $\mathrm{P}_{\mathrm{NMDG}} / \mathrm{P}_{\mathrm{Na}}$ of 0.05 , but there is no need for an increase in the $\mathrm{NMDG}^{+}$permeability, in other words, no pore dilation! The study has demonstrated that the open P2X2 ion channel permeates $\mathrm{NMDG}^{+}$as quickly as small cations like $\mathrm{Na}^{+}$, but not as easily as the latter ions. The P2X7 open ion channels also exhibit extremely low, if any, $\mathrm{NMDG}^{+}$permeability $\left(\mathrm{P}_{\mathrm{NMDG}} / \mathrm{P}_{\mathrm{Na}} \sim 0.03-0.04\right.$; Virginio et al., 1999a; Jiang et al., 2005). Structural modeling based on the open state structure of zebrafish P2X4 receptor (Hattori and Gouaux, 2012) positions the $\mathrm{C} \alpha$ atoms of three $\mathrm{S} 342$ residues in the physical gate of the ion-permeating pathway as being $6.4 \AA$ from the central axis in both rat and human P2X7 receptors (Browne et al., 2013; Jiang L.-H. et al., 2013; Figure 1D). $\mathrm{NMDG}^{+}$has a size of $6 \AA \times 6 \AA \times 12.5 \AA$ and therefore, as proposed in a recent study (Browne et al., 2013), the P2X7 open ion channels may be sufficiently wide to permeate $\mathrm{NMDG}^{+}$.

The commonly used fluorescent dyes are, however, considerably larger in size than $\mathrm{NMDG}^{+}$, for example $\mathrm{YO}$ PRO-1 $(7 \AA \times 8 \AA \times 19 \AA)$ and ethidium $(6.5 \AA \times 11 \AA \times$ $13 \AA$ ) (Browne et al., 2013). How do the fluorescent dyes come across the cell membrane, also through the ion-permeating pathway? Previous studies showed YO-PRO-1 uptake following activation of $\mathrm{P} 2 \mathrm{X} 2, \mathrm{P} 2 \mathrm{X} 2 / 3$, and $\mathrm{P} 2 \mathrm{X} 4$ receptors (Khakh et al., 1999; Virginio et al., 1999b). The open ion channels of these receptors, if permitting passage of YO-PRO-1, have to open much more widely than the above-mentioned ion-permeating pathway revealed in the open state structure of zebrafish P2X4 receptor (Hattori and Gouaux, 2012). Such a possibility remains to be tested. A recent study has investigated whether the rat $\mathrm{P} 2 \mathrm{X} 7$ ion channel was able to permeate large molecules, including the cationic fluorescent dyes YO-PRO-1 and ethidium, the anionic fluorescent dye fluorescein isothiocyanate (FITC; $8.5 \AA \times 11 \AA \times 14.5 \AA$ ), and neutral cysteine-modifying 2aminoethyl methanethiosulfonate (MTSEA; $5 \AA \times 5 \AA \times 10 \AA$ ), MTSEA-biotin $(7.5 \AA \times 8 \AA \times 18.5 \AA)$ and MTS-rhodamine $(9 \AA \times 14 \AA \times 16.5 \AA)$ (Browne et al., 2013). ATP-induced ionic currents and YO-PRO-1 uptake both strongly depend on membrane potential, the driving force for movement of charged molecules. ATP also induced uptake of ethidium and FITC in a correlating fashion even though these two dyes bear opposite charges. ATP-induced ethidium uptake was reduced and by contrast ATP-induced FITC uptake was increased by membrane depolarization. Furthermore, introduction of a positive charge by T348K mutation or neutralization of a negative charge by D352N in the small ion-permeating pathway resulted in a decrease in

\section{REFERENCES}

Bennett, J. P., Cockcroft, S., and Gomperts, B. D. (1981). Rat mast cells permeabilized with ATP secrete histamine in response to calcium ions buffered in the micromolar range. J. Physiol. 317, 335-345. doi: 10.1113/jphysiol.1981.sp013828
ATP-induced ethidium uptake but an increase in ATP-induced FITC uptake. Finally, MTSEA-biotin and MTS-rhodamine as well as MTSEA readily modified cysteine replacing G345, a position internal to the narrowest part of the P2X7 open ion channel, and inhibited ATP-induced ionic currents and ethidium uptake. These results provide direct evidence to demonstrate that the rat P2X7 open ion channel can permeate large molecules. However, to accomplish this, the open ion channels need to be a minimum of $14 \AA$ wide. This is noticeably wider than the ion-permeating pathway in the open state models of rat and human P2X7 receptors, supporting the notion that the open ion channel dilates (Virginio et al., 1999a; Browne et al., 2013). Structural determination of the ion-permeating pathway of a mammalian P2X receptor in the open state will provide the key answer to whether or how the open ion channel allows passage of fluorescent dyes.

In parallel with these efforts to understand $\mathrm{P} 2 \mathrm{X}$ receptordependent large pore formation, studies have accumulated evidence to show the importance of such receptor functionality. For example, P2X7 receptor-dependent large pore formation has been identified as a crucial factor associated with disease conditions such as chronic pain (Sorge et al., 2012), osteoporosis (Syberg et al., 2012) and geographic atrophy (Fowler et al., 2014). Furthermore, preferential inhibition of P2X7 receptordependent large pore formation has been proposed in a recent study to be the molecular mechanism underpinning the anti-inflammatory activity of nucleoside reverse transcriptase inhibitors, a class of clinically proven drugs treating HIV (Fowler et al., 2014). Selective targeting of P2X7 receptor-dependent large pore formation appears a promising and novel pharmacological intervention (Jiang, 2015). Therefore, it becomes increasingly interesting and important to gain a better mechanistic insight into large pore formation after activation of $\mathrm{P} 2 \mathrm{X}$ receptors, in particular P2X7 receptors.

\section{AUTHOR CONTRIBUTIONS}

LW, L-HJ and DL led the discussion; EC contributed to the discussion and generated the structural models. L-HJ wrote the manuscript, and all authors commented the manuscript.

\section{ACKNOWLEDGMENTS}

The research from the authors' labs described in this article has been supported in part by grants from Biotechnological and Biological Science Research Council (BB/C517317/1), Natural Science Foundation of China (81371346), Department of Education Henan Province, and start-up fund from Xinxiang Medical University. EC is a recipient of Wellcome Trust PhD studentship.

Bo, X., Jiang, L. H., Wilson, H. L., Kim, M., Burnstock, G., Surprenant, A., et al. (2003). Pharmacological and biophysical properties of the human P2X5 receptor. Mol. Pharmacol. 63, 1407-1416. doi: 10.1124/mol.63. 6.1407

Bradley, H. J., Baldwin, J. M., Goli, G. R., Johnson, B., Zou, J., Sivaprasadarao, A., et al. (2011). Residues 155 and 348 contribute to the determination of 
P2X7 receptor function via distinct mechanisms revealed by single-nucleotide polymorphisms. J. Biol. Chem. 286, 8176-8187. doi: 10.1074/jbc.M110.211284

Browne, L. E., Compan, V., Bragg, L., and North, R. A. (2013). P2X7 receptor channels allow direct permeation of nanometer-sized dyes. J. Neurosci. 33, 3557-3566. doi: 10.1523/JNEUROSCI.2235-12.2013

Browne, L. E., Jiang, L.-H., and North, R. A. (2010). New structure enlivens interest in P2X receptors. Trends Pharmacol. Sci. 31, 229-237. doi: 10.1016/j.tips.2010.02.004

Chen, J., Kim, D., Bianchi, B. R., Cavanaugh, E. J., Faltynek, C. R., Kym, P. R., et al. (2009). Pore dilation occurs in TRPA1 but not in TRPM8 channels. Mol. Pain 5:3. doi: 10.1186/1744-8069-5-3

Chung, M. K., Güler, A. D., and Caterina, M. J. (2008). TRPV1 shows dynamic ionic selectivity during agonist stimulation. Nat. Neurosci. 11, 555-564. doi: 10.1038/nn.2102

Cockcroft, S., and Gomperts, B. D. (1979). ATP induces nucleotide permeability in rat mast cells. Nature 279, 541-542 doi: 10.1038/279541a0

Compan, V., Ulmann, L., Stelmashenko, O., Chemin, J., Chaumont, S., and Rassendren, F. (2012). P2X2 and P2X5 subunits define a new heteromeric receptor with P2X7-like properties. J. Neurosci. 32, 4284-4296. doi: 10.1523/JNEUROSCI.6332-11.2012

Fowler, B. J., Gelfand, B. D., Kim, Y., Kerur, N., Tarallo, V., Hirano, Y., et al. (2014). Nucleoside reverse transcriptase inhibitors possess intrinsic anti-inflammatory activity. Science 346, 1000-1003. doi: 10.1126/science.1261754

Gomperts, B. D. (1983). Involvement of guanine nucleotide-binding protein in the gating of $\mathrm{Ca} 2+$ by receptors. Nature 306, 64-66. doi: 10.1038/306064a0

Hattori, M., and Gouaux, E. (2012). Molecular mechanism of ATP binding and ion channel activation in P2X receptors. Nature 485, 207-212. doi: 10.1038 /nature 11010

Jiang, L.-H. (2015). HIV drug nucleoside reverse transcriptase inhibitors as promising anti-inflammation therapeutics by targeting P2X7-dependent large pore formation: one stone for two birds? Front. Pharmacol. 6:38. doi: 10.3389/fphar.2015.00038

Jiang, L.-H., Baldwin, J. M., Roger, S., and Baldwin, S. A. (2013). Insights into the molecular mechanisms underlying mammalian $\mathrm{P} 2 \mathrm{X} 7$ receptor functions and contributions in diseases, revealed by structural modelling and single nucleotide polymorphisms. Front. Pharmacol. 4:55. doi: 10.3389/fphar.2013.00055

Jiang, L.-H., Rassendren, F., Mackenzie, A., Zhang, Y. H., Surprenant, A., and North, R. A. (2005). N-methyl-D-glucamine and propidium dyes utilize different permeation pathways at rat P2X7 receptors. Am. J. Physiol. Cell Physiol. 289, C1295-C1302. doi: 10.1152/ajpcell.00253.2005

Jiang, R., Taly, A., and Grutter, T. (2013). Moving through the gate in ATP-activated P2X receptors. Trends Biochem. Sci. 38, 20-29. doi: 10.1016/j.tibs.2012.10.006

Kawate, T., Michel, J. C., Birdsong, W. T., and Gouaux, E. (2009). Crystal structure of the ATP-gated P2X4 ion channel in the closed state. Nature 460, 592-598. doi: $10.1038 /$ nature 08198

Khakh, B. S., Bao, X. R., Labarca, C., and Lester, H. A. (1999). Neuronal P2X transmitter-gated cation channels change their ion selectivity in seconds. Nat. Neurosci. 2, 322-330. doi: 10.1038/7233

Khakh, B. S., and North, R. A. (2006). P2X receptors as cell-surface ATP sensors in health and disease. Nature 442, 527-532. doi: 10.1038/nature04886
Li, M., Toombes, G. E., Silberberg, S. D., and Swartz, K. J. (2015). Physical basis of apparent pore dilation of ATP-activated P2X receptor channels. Nat. Neurosci. 18, 1577-1583. doi: 10.1038/nn.4120

Munns, C. H., Chung, M. K., Sanchez, Y. E., Amzel, L. M., and Caterina, M. J. (2015). Role of the outer pore domain in transient receptor potential vanilloid 1 dynamic permeability to large cations. J. Biol. Chem. 290, 5707-5724. doi: 10.1074/jbc.M114.597435

North, R. A. (2002). Molecular physiology of P2X receptors. Physiol. Rev. 82, 1013-1067. doi: 10.1152/physrev.00015.2002

Pelegrín, P. (2011). Many ways to dilate the P2X7 receptor pore. Br. J. Pharmacol. 163, 908-911. doi: 10.1111/j.1476-5381.2011.01325.x

Pelegrin, P., and Surprenant, A. (2006). Pannexin-1 mediates large pore formation and interleukin-1beta release by the ATP-gated P2X7 receptor. EMBO J. 25, 5071-5082. doi: 10.1038/sj.emboj.7601378

Roger, S., Mei, Z. Z., Baldwin, J. M., Dong, L., Bradley, H., Baldwin, S. A., et al. (2010). Single nucleotide polymorphisms that were identified in affective mood disorders affect ATP-activated P2X7 receptor functions. J. Psychiatr. Res. 44, 347-355. doi: 10.1016/j.jpsychires.2009.10.005

Samways, D. S., Khakh, B. S., and Egan, T. M. (2008). Tunable calcium current through TRPV1 receptor channels. J. Biol. Chem. 283, 31274-31278. doi: 10.1074/jbc.C800131200

Sorge, R. E., Trang, T., Dorfman, R., Smith, S. B., Beggs, S., Ritchie, J., et al. (2012). Genetically determined P2X7 receptor pore formation regulates variability in chronic pain sensitivity. Nat. Med. 18, 595-599. doi: 10.1038/nm.2710

Steinberg, T. H., and Silverstein, S. C. (1987). Extracellular ATP ${ }^{4-}$ promotes cation fluxes in the J774 mouse macrophage cell line. J. Biol Chem. 262, 3118-3122.

Surprenant, A., Rassendren, F., Kawashima, E., North, R. A., and Buell, G. (1996). The cytolytic P2Z receptor for extracellular ATP identified as a P2X receptor (P2X7). Science 272, 735-738. doi: 10.1126/science.272.5262.735

Syberg, S., Schwarz, P., Petersen, S., Steinberg, T. H., Jensen, J. E., Teilmann, J., et al. (2012). Association between P2X7 receptor polymorphisms and bone status in mice. J. Osteoporos. 2012:637986. doi: 10.1155/2012/637986

Virginio, C., MacKenzie, A., North, R. A., and Surprenant, A. (1999b). Kinetics of cell lysis, dye uptake and permeability changes in cells expressing the rat P2X7 receptor. J. Physiol. 519, 335-346. doi: 10.1111/j.1469-7793.1999.0335m.x

Virginio, C., MacKenzie, A., Rassendren, F. A., North, R. A., and Surprenant, A. (1999a). Pore dilation of neuronal P2X receptor channels. Nat. Neurosci. 2, 315-321. doi: 10.1038/7225

Yan, Z., Li, S., Liang, Z., Tomic, M., and Stojilkovic, S. S. (2008). The P2X7 receptor channel pore dilates under physiological ion conditions. J. Gen. Physiol. 132, 563-573. doi: 10.1085/jgp.200810059

Conflict of Interest Statement: The authors declare that the research was conducted in the absence of any commercial or financial relationships that could be construed as a potential conflict of interest.

Copyright (C) 2016 Wei, Caseley, Li and Jiang. This is an open-access article distributed under the terms of the Creative Commons Attribution License (CC BY). The use, distribution or reproduction in other forums is permitted, provided the original author(s) or licensor are credited and that the original publication in this journal is cited, in accordance with accepted academic practice. No use, distribution or reproduction is permitted which does not comply with these terms. 